\title{
LA DOBLE RUPTURA: PROBLEMAS EPISTEMOLÓGICOS A PARTIR DE LA CONSTRUCCIÓN DE UNA BASE DE DATOS HISTÓRICA RELATIVA A LA CONVERSIÓN FORZADA
}

\section{THE DOUBLE BREAK: EPISTEMOLOGICAL PROBLEMS DERIVED FROM THE CONSTRUCTION OF A HISTORICAL DATABASE RELATED TO FORCED CONVERSION}

\author{
Marisa Bueno Sánchez \\ Université Paris-Est Créteil \\ marisa.bueno@univ-nantes.fr
}

Nicolas Perreaux

Goëthe-Universität Frankfurt am Main

nicolas.perreaux@free.fr

\section{Resumen}

Este artículo muestra algunos problemas epistemológicos derivados de la explotación de los textos recogidos en el proceso de creación de la base de datos del proyecto POCRAM, (http://pocram.hypotheses.org/), relativa a la cuestión de la conversión religiosa entre la Antigüedad tardía y el fin de la Edad Moderna. Así mismo, se hace un balance de la evolución de las Humanidades Digitales (especialmente en Francia), así como de los proyectos precedentes en que se inspira la conceptualización de la base. Presentamos nuestro corpus y las consecuencias de su explotación gracias al uso de diferentes softwares que provocan una doble ruptura, epistemológica y conceptual, en la forma de entender la historia. 
Palabras clave: Conversión religiosa. POCRAM. Antigüedad tardía. Edad Moderna.

\begin{abstract}
This paper contains some reflections about epistemological questions derived from the exploitation of texts collected in the POCRAM database (http://pocram.hypotheses.org/), a corpus concerning religious conversion between Late Antiquity to the end of Modern Age. Furthermore, we present the evolution statement of Digital Humanities (especially, in France), as well as the previous projects that inspire our conceptual choice. We present our corpus and the consequences of its exploitation, through the use of different software, leading to a double break both, epistemological and conceptual, in the way of understanding history.
\end{abstract}

Keywords: Religious Conversion. POCRAM. Late Antiquity. Modern Age.

\title{
1. LA ERA DIGITAL: LOS NUEVOS PARADIGMAS DE INVESTIGACIÓN
}

La informática abre nuevas puertas a la investigación y propone modelos de trabajo que han revolucionado la práctica de la construcción de los discursos históricos en los últimos diez años. Lo que se conoce como Digital Humanities (DH) se inscribe en el cruce disciplinar entre las Ciencias Sociales y las nuevas tecnologías informáticas. Si bien el término DH surge a partir de la obra A Companion to Digital Humanities (Schreibman et al., 2004), el debate sobre su definición se encuentra en constante evolución (Stevens y Moorman, 2006; Deegan y Sutherland, 2009), produciéndose un cambio discursivo entre Humanities Computing y Digital Humanites en función de la evolución tecnológica, haciendo uso de la distinción entre Web 1.0 y Web 2.0 (Davidson, 2008: 707-717; Svensson, 2009). La relación entre las Humanidades y la Informática es evolutiva, tal y como señala Svensson en múltiples publicaciones, considerándose en muchos casos la informática como herramienta, objeto de estudio, medio de expresión, laboratorio experimental o como sistema de difusión del conocimiento (Svensson, 2010; 2011). Aunque la integración de ambas disciplinas es difícil, la fusión supone "a field and arena for innovation and rethinking humanities" (Svensson, 2012). En realidad, la necesidad de autorreflexión y autodefinición es intrínseca a la naturaleza de las $\mathrm{DH}$, una naturaleza en constante cambio en función de la evolución tecnológica. (McCarty, 2003: 1233). Al problema de la constante definición hay que sumar la unificación de las 
prácticas, casi siempre impuestas por los modelos anglófonos, no siempre adaptadas a los problemas y circunstancias de países de lenguas latinas (Priani Saisó et al., 2014: 5-19).

Aunque el concepto DH no fue acuñado hasta el 2004, la relación entre Informática y las Humanidades se remonta a experiencias que comienzan a mediados del siglo XX. Se suele considerar al jesuita Roberto Busa (1913-2011) como el fundador de la disciplina, en 1949, a través de la creación del Index Thomisticum -en colaboración con IBM-, donde realiza la lematización de las obras de santo Tomás de Aquino, un proyecto que duró 30 años sintetizado en un CD (Busa, 1992) que más tarde fue migrado a la red ${ }^{1}$. En los años 19601970 otros investigadores empezaron a trabajar concordancias entre textos: Dolores Burton y Roy Wisbey produjeron una serie de índices, para el análisis de los textos de la Alta Edad Media alemana, creando en Cambridge el Centre for Literary and Linguistic Computing en 1963, y Stephen Parrish realizó las concordancias entre los poemas de Mathew Arnold y Yeats (Hockey, 2004).

La eclosión de las pre-DH en Francia se produce en los años 60'. En 1966 se crea la revista Computers and the Humanities y aparece, en paralelo, el Centre de Recherche d'Application Linguistiques (CRAL) en la Universidad de Nancy, donde se desarrolla el Trésor de la Langue Française a partir de material literario recopilado (Gorcy, 1983: 119-144). Desde 1983 L'Atelier de Recherche sur le Textes Mediévéles (ARTEM) continúa la antigua labor del CRAL. La experiencia de Nancy es paralela a otras en Francia; en 1974, cuando se crea en Poitiers un grupo dedicado al análisis de textos a partir de medios informáticos (Bourlet, 1979: 11-12). En 1979 surge la revista Le Médiéviste et l'Ordinateur, creada en el IRHT (Institut de Recherche des Textes), por medievalistas interesados en la aplicación de las nuevas tecnologías informáticas en su reflexión histórica, y después de 1986, la revista Histoire \& Mesure (Genet, 1986: 7-18). Esta última revista propone una reflexión continua sobre el uso de los métodos estadísticos como sistema de medida y evolución de los fenómenos históricos de todo tipo, político, culturales, económicos, sociales, y propone, al mismo tiempo, un análisis conjunto de las fuentes y los métodos (Fossier, 1991: 501-525; Genet, 2011: 1-9). En la reunión de la École Française de Rome de 1975 se planteaba el uso de la informática como herramienta metodológica en diversos campos de la historia medieval, el tratamiento de corpus diplomáticos y sus problemas de lematización, aplicación para la historia social y política (Fossier et al., 1977).

La creación del sitio web Menestrel', en línea después de 1997, ha sido una herramienta básica para la introducción de la historia en la era digital. Si bien el término $\mathrm{DH}$ se acuña como tal en el año 2004, debería hablarse no de un nacimiento sino de nacimientos de la disciplina, de un entusiasmo a la vez real y fragmentado (Perreaux, 2014: 187-211). Es

\footnotetext{
${ }^{1}$ Accesible desde http://www.corpusthomisticum.org/.

${ }^{2}$ Accesible desde http://www.menestrel.fr/.
} 
decir, los medievalistas han percibido muy pronto la utilidad de estos métodos, pero sólo tuvieron efecto entre los años 60' y 80'. Gran parte de las ideas de esos momentos han sido reconsideradas años después en las discusiones posteriores debido a la evolución de la tecnología (Gardin, 1994: 18); el aumento de las memorias de almacenamiento y de la velocidad de los procesadores permiten tratar los grandes conjuntos textuales (Guerreau, 2012; Weller, 2012; Clavert y Noiret, 2013).

A partir del año 2000 el impacto académico de la disciplina fue remarcable. El desfase temporal se debe fundamentalmente a la reticencia de los medios académicos para reconocer la utilidad de las ciencias duras como sustrato metodológico de las Humanidades. En el 2006 el CNRS (Centre National de la Recherche Scientifique) creó cuatro centros nacionales de fuentes digitales destinados a coordinar proyectos de digitalización y tratamiento de los datos informáticos de forma evolutiva ${ }^{3}$. El número de experiencias sobre edición de textos y documentos históricos se multiplica en los últimos años en el ámbito francés. El consorcio COSME, Consortium Sources Médievales (TGIR-Huma-Num, CNRS), trata de favorecer la publicación electrónica de distintos corpus numéricos y al mismo tiempo favorecer la interrogación conjunta unificando las normas de digitalización y etiquetado ${ }^{4}$. Un gran número de proyectos relativos a la edición numérica de fuentes históricas se albergan en el IRHT, entre otros: Répertoire des Cartulaires Médiévaux et Modernes ${ }^{5}$, Corpus Luxury Bound, dedicado a manuscritos ilustrados holandeses entre 1400 y 1550, Catalogue des Manuscrits Litúrgiques $^{6}$, así como múltiples bases de datos, como la BVMN, Bibliothéque Virtuelle des Manuscrits Médiévales ${ }^{7}$.

Si bien nos concentramos en la experiencia francesa, actualmente la disciplina se desarrolla en diversos laboratorios europeos. En el ámbito germánico, el Instituto Histórico Alemán $(\mathrm{AHA})^{8}$; la Universidad de Colonia donde se desarrolla el proyecto sobre Codicología y Paleografía en la era digital (Rehbein et al., 2009); el Frankfurt Digital Humanities ProjectHistorical Semantics Corpus Management (HSCM), en la Goethe Universidad de Frankfurt, que desarrolla un ambicioso proyecto que mezcla Lingüística e Historia (Jussen et al., 2007: 81-89; Jussen et al., 2011: 97-117); el Centro Austríaco para las Humanidades Digitales, donde se destaca el trabajo de Georg Vogeler en lo que concierne a la diplomática medieval (Vogeler, 2009; Kemper y Vogeler, 2011). En Inglaterra rápidamente encontró un campo de aplicación específico el laboratorio de DH del King's College (Londres), que alberga doce

\footnotetext{
${ }^{3}$ CN2SV (Centre National pour la Numérisation de Sources Visuelles), TELMA (Traitement Electronique des Manuscrits et des Archives), CRDO (Centre de Ressources pour la Description de l'Oral), CNRTL (Centre National des Ressources Textuelles et Lexicales).

${ }_{5}^{4}$ Accesible desde https://cosme.hypotheses.org/category/corpus-et-projets.

${ }^{5}$ Accesible desde http://www.cn-telma.fr/cartulR/index/.

${ }_{7}^{6}$ Accesible desde http://www.cn-telma.fr/liturgie/index/.

${ }^{7}$ Accesible desde http://bvmm.irht.cnrs.fr.

${ }^{8}$ Accesible desde htps://dhiha.hypotheses.org.
} 
proyectos de diversa naturaleza, de la edición de manuscritos al análisis de la edad de los metales (Kirschenbaum, 2010: 1-7; Pierazzo et al., 2010). En España la reciente creación del Laboratorio de Innovación en Humanidades Digitales (LINHD-UNED) consolida la disciplina, que por el momento goza de un mayor desarrollo entre los lingüistas y filólogos que entre los historiadores (González-Blanco, 2013: 53-68; 2016: 79-93; Borsari y Calvo Tello, 2013: 203226).

Si bien la disciplina es comúnmente aceptada, se alzan voces contra la aplicación de las tecnologías informáticas en el campo de las Ciencias Humanísticas, lo que hace que el debate sea creciente (Marche, 2012; Hall, 2012: 133-136).

No es nuestro objetivo hacer balance historiográfico del panorama europeo, sino simplemente remarcar la implantación en el ámbito de los estudios históricos y establecer una reflexión a partir de nuestra participación en la creación de la base de datos del mencionado Proyecto POCRAM, Povouir et conversion religieuse de l'antiquité a la periode moderne, actualmente en curso de realización. El objetivo de este programa es incrementar la reflexión teórica sobre las tipologías de comportamientos sociales de cara a la conversión religiosa, lo que permite abordar la cuestión de la conversio como un elemento de transformación de las sociedades. En este sentido, se optó por la creación de una base de datos que nos introduce en la reflexión teórica y en los nuevos retos que plantean las Humanidades Digitales en el campo histórico. Una gran cantidad de artículos científicos ponen de manifiesto los problemas comunes del paso de los textos a los datos digitales: indexación, modelado textual, transformación de la interfaz de análisis (Romanello et al., 2009: 155-174; Guerreau, 2012). En todos los casos, el uso de las herramientas informáticas modifica profundamente las prácticas de los historiadores (Genet, 2011: 4). La edición digital de textos nos obliga a una mayor reflexión en la edición científica, potencialmente más exhaustiva que un libro, un facsímil o una simple edición HTML, ya que la necesidad del etiquetado de textos permite una multiplicidad de puntos de vista sobre el análisis textual y un grado de interrelaciones léxicas que multiplican el número de hipótesis de trabajo, que el análisis textual clásico no permite. El etiquetado es una actividad científica en sí misma que permite un protagonismo de las fuentes y una mayor capacidad de reflexión teórica. La utilización de las herramientas informáticas y nuevas tecnologías de la información nos precipitan nuevamente sobre las fuentes primarias, y eliminan de la producción científica la práctica conformista de la réplica intelectual y la glosa académica a través del libre acceso de las fuentes (Le Clech, 2012; Guerreau, 2015; Dulong de Rosnay, 2016). 


\section{EXPERIENCIAS PREVIAS Y MODELO CONCEPTUAL}

Desde el principio nos vimos confrontados a la toma de decisiones. ¿Debíamos crear una base de datos como colección de noticias o una base de datos de investigación que nos permitiera analizar y manipular los textos sobre múltiples criterios?

La creación de una base de datos a partir de una compilación de fragmentos extraídos de diferentes fuentes parecía la solución más simple, siguiendo los modelos de las recopilaciones textuales del siglo XIX, pero en formato digital. Experiencias previas y en curso de estos modelos conceptuales de corpus online son de gran utilidad para el investigador, ya que permiten agilizar la producción científica, el acceso a noticias concretas y favorecen la multidisciplinariedad del discurso histórico, al recoger fuentes de distintas tradiciones lingüísticas y culturales. En este sentido, los corpus más sobresalientes y conexos con el tema de la conversión religiosa son $\mathrm{RELMIN}^{9}$, Le statut légal des minorités religieuses dans l'espace euro-méditerranéen ( $V^{\text {ème }}-X V^{\text {ème }}$ siècles), y el corpus en curso de realización del Center for the Study of Conversion and Intereligious Studies de la Ben Gurion University de Negev ${ }^{10}$. En ambos casos se realizó una interfaz de interrogación que permite el acceso a las diferentes noticias a través de un glosario, poniendo en relación textos de diferentes tradiciones y lenguas mediante el desarrollo de hipervínculos internos en la base de datos.

Si bien esta solución parecía más ventajosa y de una mayor simplicidad técnica, ya que sólo habría que etiquetar diversas palabras clave a partir de un volumen de textos reducido, en el plano disciplinar la solución nos pareció insuficiente, teniendo en cuenta las múltiples posibilidades de análisis que supone el tratamiento integral de las fuentes completas. Este tipo de tratamiento evita el subjetivismo de la selección de fragmentos realizada por el investigador en la fase previa a su tratamiento digital, y que pueden condicionar el resultado de la investigación.

Optamos por el diseño de una base de datos técnica en la que se integraran los textos completos, el objetivo de partida es doble: por un lado, la construcción de una base de datos que permita la explotación estadística y lexicográfica (de tipo Big Data/Data/Text Mining) (Witten et al., 2011; Manning et al., 2008), y al mismo tiempo facilitar la investigación textométrica y semántica sobre la cuestión de la conversio. Con esta opción se garantizaba la re-contextualización de las formas y la comprensión de la relación entre la conversión religiosa y los poderes en una perspectiva de historia comparada en longue durée (Braudel, 1958: 725753; Wallerstein, 2004; Goody, 2006; Boucheron y Delalande, 2013).

Algunas de las experiencias de bases de datos realizadas previamente, permitían poner en evidencia el uso de nuevos paradigmas históricos, gracias a la utilización de

\footnotetext{
${ }^{9}$ Accesible desde http://www.cn-telma.fr/relmin/index/.

${ }^{10}$ Accesible desde http://in.bgu.ac.il/en/csoc/Pages/Conversion-Database.aspx.
} 
herramientas de investigación novedosas (motores de búsqueda sobre gran cantidad de corpus textuales, concurrencias, lexicogramas, modelización, etc.). Estas bases de datos previas realizadas a partir de la digitalización y edición de diferentes corpus textuales fueron la inspiración de nuestro modelo conceptual. Entre ellas, el corpus de Chartes originales antérieures à 1121 conservées en France ${ }^{11}$. Se trata de un corpus documental en línea, que recoge fundamentalmente actos jurídicos escritos, es decir, actas de donación de venta o de intercambio y procesos judiciales hasta el siglo XIII. La base de datos permite la búsqueda de documentos en función de su autor o de su destinatario, pero el verdadero objeto de la base es el análisis lexical que permite detectar falsificaciones y originales (Tock, 2001: 1-37) ${ }^{12}$.

Otra experiencia que fue más allá de la simple recopilación textual, es la Charta Burgundia Medievun Aevi (CBMA), que promueve y coordina el estudio de la documentación diplomática medieval de Borgoña (Magnani y Gasse-Grandjean, 2005: 179-181; 2007: 163169; 2008: 237-244; 2009: 245-251 y 2010: 197-209; Magnani et al., 2013: 27-30; Perreaux y Rey, 2013). Los resultados están disponibles en una plataforma documental y en una base de datos de actas diplomáticas accesibles libremente en diferentes formatos electrónicos ${ }^{13}$. Se trata de corpus con más de 15.000 diplomas interrogable con el programa Philologic ${ }^{14}$, lo que supone un terreno experimental para nuevos métodos de investigación, y que permite no sólo la acumulación de los datos sino la explotación de los mismos (Perreaux, 2014: 187-211). Este tipo de bases de datos permiten una interrogación de diversos campos semánticos en función de los intereses del investigador. En el caso del CBMA, las temáticas suscitadas son múltiples: el agua (Perreaux, 2011: 439-449); el intercambio (Magnani, 2013: 403-426); el diezmo (Rosé, 2008).

Actualmente, existe un desajuste entre la cantidad de datos disponibles en línea y la explotación de los mismos, lo que evidencia una inadaptación del método histórico tradicional al nuevo material disponible. Esta inadaptación no podrá ser superada hasta que no se pongan a disposición de la comunidad científica, instrumentos técnicos que permitan el análisis conjunto de la documentación. Alain Guerreau hacía eco de este desajuste y de la necesidad de una doble ruptura en el plano metodológico y en el plano epistemológico, así como la importancia de la semántica histórica en el campo de la historia medieval, a fin de reposicionar los conceptos en sus contextos de origen (Guerreau, 2001a: 87-90; 2001b: 6773). El salto metodológico lleva implícito un salto epistemológico, y nuevas preguntas asociadas a los fenómenos históricos y la contextualización de los mismos. Un buen ejemplo

\footnotetext{
${ }^{11}$ Accesible desde http://www.cn-telma.fr//originaux/index/.

${ }_{12}^{12}$ Después de 2011 el corpus se puso online http://www.cn-telma.fr/originaux/colophon.

13 Accesible desde http://www.cbma-project.eu, y accesible desde: http://philologic.cbma-project.eu/.

${ }^{14}$ Utilizado en Bibliothèque nationale de France (BnF), http://gallica.bnf.fr, y Biblioteca Nacional de España (BNE), http://www.bne.es/es/Catalogos/BibliotecaDigitalHispanica//nicio/.
} 
en esta línea, constituyen los estudios que muestran la correlación entre la existencia de edificios románicos y la producción documental en la Edad Media (Perreaux, 2015; en prensa).

El campo semántico (Trier, 1931; Schmidt, 1973; Castagnoli, 1987) de la conversión es complejo, así como su variedad de significantes. Su valor semántico mayoritario se asocia al cambio de credo (en el Diccionario de la RAE se trata su primera acepción), provocando una sinécdoque histórica que distorsiona el valor de los conceptos. La re-contextualización del lema conversio permite eliminarlo de sus adherencias historiográficas que lo asocian casi exclusivamente a los procesos de cambio de credo impulsados por el poder político en su afán de unidad religiosa y construcción identitaria uniforme en diversos momentos históricos y espacios geográficos diversos, entre otros: conversión de los francos tras el bautismo de Clovis, la conversión al cristianismo de musulmanes y judíos en la España del siglo XV, y los cismas luteranos y anglicanos en el siglo XVI. Después de estas reflexiones se optó por un modelo de base de datos de las siguientes características:

- Abierta a la mayor parte de investigadores y centros universitarios.

- Experimental, en el sentido de que la misma debería permitir las manipulaciones formales precisas para la explotación semántica, lexicográfica de los datos masivamente.

- Open Access, para difundir los textos íntegros de la base tras su construcción, conciliando la difusión de resultados y la ambición científica.

\section{CRITERIOS DE ELECCIÓN DEL CORPUS TEXTUAL}

La concepción teórica de la base de datos como un gran corpus integrado por textos completos de diversa naturaleza: normativos (jurídico-eclesiásticos), teológicos, documentos de la práctica jurídica, no se agota en la corta vida de los cuatro años que dura un proyecto de investigación. La documentación textual es muy numerosa y extraordinariamente dispersa, por la que la integración de la totalidad de textos es una aspiración idílica. Las dimensiones del corpus contaban con una serie de problemas: una cronología muy amplia, de la Antigüedad tardía hasta el siglo XVII; una amplia cobertura geográfica, de Europa al Nuevo Mundo y hacia el este asiático; plurilingüismo, documentos en griego, latín, romance, español, francés, inglés. La existencia de estos parámetros de partida aumentó las dificultades técnicas, que conviene señalar con el objetivo de construir un marco de investigación satisfactorio.

El protagonista es el texto, abordando una perspectiva foucaultiana en el análisis del discurso de la conversión. La cuestión de la recontextualización terminológica no es banal, su objetivo es reposicionar los vocablos en su momento de creación ya que las condiciones del 
discurso cambian en función del tiempo y del lugar geográfico, mutando en múltiples ocasiones el sentido del épistémé (Foucault, 1966: 330-332; Robin, 1973).

\subsection{Selección de corpus y sub-corpus}

La enorme cantidad de textos y las posibilidades de deformación de resultados obligó desde el principio, a establecer criterios de selección de los textos en función de las circunstancias históricas, de los diferentes períodos y distintas áreas geográficas. Una comparativa en la longue durée implicaba necesariamente la creación de sub-corpus homogéneos cualitativamente, cuantitativamente densos y con límites bien definidos y controlados, que nos permitiese abordar el fenómeno de la conversión desde una perspectiva comparada. Esta selección obedecía fundamentalmente al objetivo inicial de la base de datos: la creación de un instrumento de análisis que permitiera la re-contextualización de las formas, modos y consecuencias de la conversión religiosa impulsada desde el poder político, desde una perspectiva de la historia comparada.

Actualmente existe un gran volumen de datos en línea gracias a la puesta en red de un gran número de textos por las grandes bibliotecas $(\mathrm{BnF}, \mathrm{BNE})^{15}$, y de repositorios digitales ${ }^{16}$ que en algunos casos permitían el acceso al texto completo en formato TXT, HTML, lo que permite una mayor flexibilidad en el posterior tratamiento del texto. Se observó que el número de textos en formatos libres eran más abundantes para los periodos altomedievales. La existencia de un mayor número de ediciones electrónicas de textos latinos, pone de manifiesto el interés de los filólogos en las ediciones digitales, y un mayor avance en la disciplina en este campo. Los textos utilizados corresponden a ediciones antiguas, todos ellos libres de derechos de autor. En este punto la legislación es clara: si la fecha de muerte de los autores del texto es superior a 70 años, una nueva edición crítica sobre su obra no abre derechos de autor sobre el texto editado, sino solamente sobre el aparato crítico de la obra (Guerreau, 2015; Dulong de Rosnay, 2016) ${ }^{17}$. Se trata de:

- Conversión en la Antigüedad tardía y de la Alta Edad Media (siglos III-IX), tomando como punto de partida el trabajo de Bruno Dumezil (2005): Se incluyen textos

\footnotetext{
15 Accesibles desde http://www.thelatinlibrary.com, https://www.hsaugsburg.de/ harsch/augustana.html\#la y http://penelope.uchicago.edu/Thayer/E/Roman/home.html. Esta cuestión provocó recientemente toda una sesión de discusiones en el IRHT. Véase: "L'éditeur de textes est-il un auteur? Réflexions juridiques et scientifiques à propos de l'édition critique" en http://www.irht.cnrs.fr/fr/agenda/l-editeur-de-textes-est-il-un-auteur, https://cahier.hypotheses.org/2031. Accesible desde

http://www.documentacatholicaomnia.eu/18151875, Migne, Patrologia Latina 01. Rerum Conspectus Pro Tomis Ordinatus, MLT.html.

"Accesible desde http://www.documentacatholicaomnia.eu/25 90 1643-1925-_Acta Sanctorum.html.
} 
fundamentalmente en latín, a partir de la Patrologia Latina ${ }^{18}$, Acta Sanctorum $^{19}$ y de los Monumenta Germaniae Historica $(\mathrm{MGH}-\mathrm{dMGH})^{20}$. Más de 100 textos han sido recopilados en la base de datos que corresponden a más de 6.000 .000 de palabras.

- Corpus teológico en torno a la conversión religiosa en la Edad Media: Esta compilación permite analizar las líneas directrices de la Iglesia durante el período. Partimos para ello del Corpus luris Canonici, cuya edición digital en su versión facsímil de 1582 se encuentra disponible en el repositorio de Canon Law de la biblioteca de la UCLA $^{21}$. Teniendo en cuenta el enorme trabajo de transformación de los ficheros en formato imagen, resultó de mayor utilidad el uso de ediciones impresas posteriores, tanto del Decretum Gratiani como del Liber Extra (Friedberg, 1879; Friedberg y Richter, 1881). Así mismo, se hizo una selección de los teólogos medievales que en sus obras trataban la cuestión de la conversión, como la Summa Theologica de Tomas de Aquino (De Aquino, 1888), Adversus ludeos de Joachim de Fiori (Frugoni, 1957), el Defensor Pacis de Marsilio de Padua (Scholz, 1931) y las Actas de los Concilios de Letrán (Alberigo, 1973), entre otros.

- Conversión en la Península Ibérica: La amplitud cronológica (siglos VIII-XV) y la gran cantidad de textos relativos al problema religioso en la Edad Media hispánica, implica una labor de selección textual. Se han recogido textos jurídicos y teológicos entre los siglos $\mathrm{X}-\mathrm{XV}$, incluyendo gran parte de la cronística hispana, legislación foral y real, y textos teológicos de diversos autores con el fin de analizar la importancia del fenómeno de la conversión y de sus efectos socio-políticos. El número de ediciones electrónicas de fuentes históricas en línea para este corpus no es muy abundante. Entre las fuentes digitales disponibles para el período medieval se encuentra la edición digital del Becerro Galicano (Peterson, 2009: 653-682; Álvarez Carbajal, 2014) así como la edición del Liber Regnum (Thieulin-Pardo, 2010). El fenómeno de la conversión forzada entre los siglos XIV-XVI genera una de las temáticas de análisis más ricas en la historia hispana. La masiva conversión de judíos especialmente intensa a partir de la mitad del siglo XIV (Nirenberg, 2014: 143-169) y la conversión de los moriscos a principios del XVI (Poutrain, 2012) hacen que el espacio geográfico peninsular adquiera un especial protagonismo en la selección de fuentes. El mayor número de textos corresponde a este período, según las bases textuales aportadas por Rica Amrán y Jeremy Cohen en lo que se refiere a las polémicas entre judíos, conversos y cristianos (Amrán, 2009; Cohen, 1991), mientras que para los mudéjares

\footnotetext{
${ }_{10}^{18}$ Accesible desde http://www.dmgh.de.

${ }_{19}^{19}$ Accesible desde el UCLA Digital Library Program, http://digital.library.ucla.edu/canonlaw.

${ }^{20}$ Accesible desde http://www.hum.huji.ac.il/english/units.php?cat=4041\&incat=4032.

${ }^{21}$ Accesible desde http://www.cervantesvirtual.com/.
} 
se ha partido de las obras de Fernández y González (1866); los trabajos recientes de Ana Echevarría Arsuaga (2006: 7-30) y Ana Isabel Carrasco Manchado (2012). Se incluyen también en este corpus algunos documentos derivados de la práctica jurídica relativos a la conversión de los judíos y que forman parte de los trabajos de Haim Beinart disponibles en línea en la biblioteca virtual Hispania Judaica, de la Universidad Hebrea de Jerusalén (Baer, 1929-1936; De la Torre, 1962; Suárez Fernández, 1964$)^{22}$. - Conversión de las nuevas tierras: Tras el descubrimiento de América la cuestión de la conversión de los indios fue crucial, la cuestión estaba ya apuntada en las disposiciones de Isabel la Católica, y durante el siglo XVI el hecho de la instrucción de los indios en la santa fe católica fue una cuestión prioritaria tanto en las crónicas de la conquista, como en la legislación civil y eclesiástica del período. Una vez más encontramos una gran dispersión de fuentes, algunas presentes en colecciones digitales como las Cartas de relación de Hernán Cortés a partir de colecciones documentales del siglo XIX (García Icazbalceta, 1858), pero en la mayor parte de los casos los textos provienen de la Biblioteca Virtual Miguel de Cervantes ${ }^{23}$. Las fuentes que provienen de esta última biblioteca virtual se encuentran en diferentes formatos, $\mathrm{XML}, \mathrm{PDF}$, por lo que en todos los casos los textos exigen un trabajo previo de limpieza y homogeneización. El análisis conjunto de textos cronísticos como La Historia verdadera de la Nueva España de Bernaldo Díaz del Castillo (1930), la Historia de los Indios de la Nueva España de Fray Toribio de Benavente (1913), la Brevísima relación de la destrucción de las Indias de Bartolomé de las Casas (1821) junto a las instrucciones regias como las Leyes de Burgos de Fernando de Aragón de 1512, o las Leyes y ordenanzas para el buen tratamiento de los indios de Carlos I (1523) permiten establecer un diálogo entre la norma y las realidades cotidianas en lo referente a la instrucción y conversión de indios en Nueva España.

- Corpus de las guerras de religión en Francia (1562-1580). Se trata de un corpus de diecisiete textos relevantes relativos a los conflictos entre católicos y protestantes entre el reinado de Enrique II y el de Enrique IV, donde el Edicto de Nantes de 1589 tiene especial relevancia (Crouzet, 2008: 75-342). Para la elaboración de este corpus, diversas colecciones han sido de gran utilidad (Fontanon, 1611: 267-269; 272-274; 289-291; 292-294; 300-304; 307-315; 318-326; 330-335; 335-340; 340-342; 361-363; Isambert et al., 1829a: 377- 475; Isambert et al., 1829b: 190-196), así como las ediciones electrónicas de l'École des Chartes ${ }^{24}$.

\footnotetext{
22 Se trata de "L'édit de Nantes et ses antécédents (1562-1598)", accesible desde http://elec.enc.sorbonne.fr/editsdepacification/.

${ }^{23}$ Accesible desde http://www.geany.org/.

${ }^{24}$ En particular, QGIS: http://www.qgis.org/fr/site/.
} 
En definitiva, por el momento, en la base de datos preliminar están recopilados 300 textos. El desequilibrio de los textos disponibles online que pueden ser directamente utilizados, se acentúa en función de las cronologías y espacios de análisis en función de los proyectos y experiencias previas. Este desequilibrio es remarcable en los textos que corresponden a la Alta Edad Media y la Antigüedad tardía, casi todos ellos disponibles en red a través de la $\mathrm{MGH}$. Sin embargo, el número de fuentes disponibles es menor para los períodos medievales y de la Edad Moderna. Los textos de los siglos XIV y XV han sido escasamente informatizados y puestos a disposición del público, y gran parte de los mismos son encontrados en formato imagen lo que ralentiza la construcción del corpus.

\subsection{Manipulaciones previas a la edición textual}

Un gran número de textos se encontraba disponible en PDF, o en modo imagen, han sido directamente escaneados de las ediciones a nuestro alcance, lo que ha hecho necesario una primera transformación del formato original del texto en TXT con un programa OCR, herramienta que a pesar de su evolución no es aún óptima ya que implica muchos errores, situación que requiere inevitablemente una relectura de los textos y limpieza manual de los mismos. Algunas herramientas y programas facilitan el proceso, como el programa Geany ${ }^{25}$, y sobre todo la programación (Perl, Python), que permiten una primera formalización y uniformización de los textos. En general, diversos programas permiten extraer los textos, pero en ningún caso, es posible evitar su limpieza posterior (Guerreau, 2012).

\section{LA ESTRUCTURACIÓN DE LOS DATOS HISTÓRICOS. BALIZAJE Y FORMALIZACIÓN DE TEXTOS}

La constitución de un corpus digital precisa pensar previamente los modos de interrogación de la futura base de datos, lo que condicionará la futura indexación de los ficheros. La formalización textual es esencial, ya que de esta fase depende el futuro de la explotación de los textos. En vista de los objetivos definidos por el proyecto, una solución de balizaje mínimo ha resultado como la más operativa y provechosa, y debía ser compatible con la gran cantidad de textos a integrar. El número de campos por cada texto ha sido limitado a fin de controlar mejor esta primera fase. Trece elementos aparecen en las primeras balizas de clasificación de los textos:

\footnotetext{
${ }^{25}$ En el proyecto Omnia de la ANR: Outils et Méthodes Numériques pour l'Interrogation et l'Analyse des textes médiolatins. Accesible desde http://www.agence-nationale-recherche.fr/projetanr/?tx Iwmsuivibilan_pi2\%5BCODE\%5D=ANR-08-BLAN-0134.
} 
- Contenido: texto/imagen/url para la iconografía (en el caso de manuscritos iluminados).

- Referencias: bibliografía de la edición, título del documento, autor en caso de que sea conocido.

- Datación: terminus ad quem, terminus ante quem, fecha completa en caso de que sea conocida. Este sistema permite el posterior tratamiento formalizado que necesita de modo regular la existencia de cuatro cifras.

- Tipología documental: categoría (texto, iconografía,) y subcategoría (texto teórico, normativo-jurídico o eclesiástico; de la práctica jurídica, incluye material de archivo), hagiográfico, narrativo, etc.

- Localización: país actual de redacción del texto o documento, lugar preciso, coordenadas GPX (sistema WGS-84), que permiten exportar los datos con el fin de construir una geografía de la conversión, y facilitar al mismo tiempo la consulta de los datos asociándolos a un mapa, a través del uso de un programa $\mathrm{GIS}^{26}$.

En el estado actual, los datos integrados poseen todos estos descriptores. Algunas investigaciones han sido necesarias ya que en ocasiones hay textos mal datados, de difícil o dudosa cronología, lo que implica un análisis bibliográfico por cada texto.

Como se ha señalado anteriormente, el tratamiento de los textos exige el uso de ficheros en formato XML, que han dado lugar a diferentes fases de limpieza antes de ser integrados en una primera base de datos preliminar en FileMaker. Esta elección ha constituido una etapa intermedia inicial antes de la definición del alojamiento institucional del corpus en la plataforma final. FileMaker es relativamente flexible en lo que se refiere a la exportación de los datos. Dicho programa permite al equipo, la integración de los documentos en la base de datos antes de su conversión para la migración al servidor en línea.

\footnotetext{
${ }^{26}$ Trabajamos actualmente en un artículo sobre esta cuestión.
} 


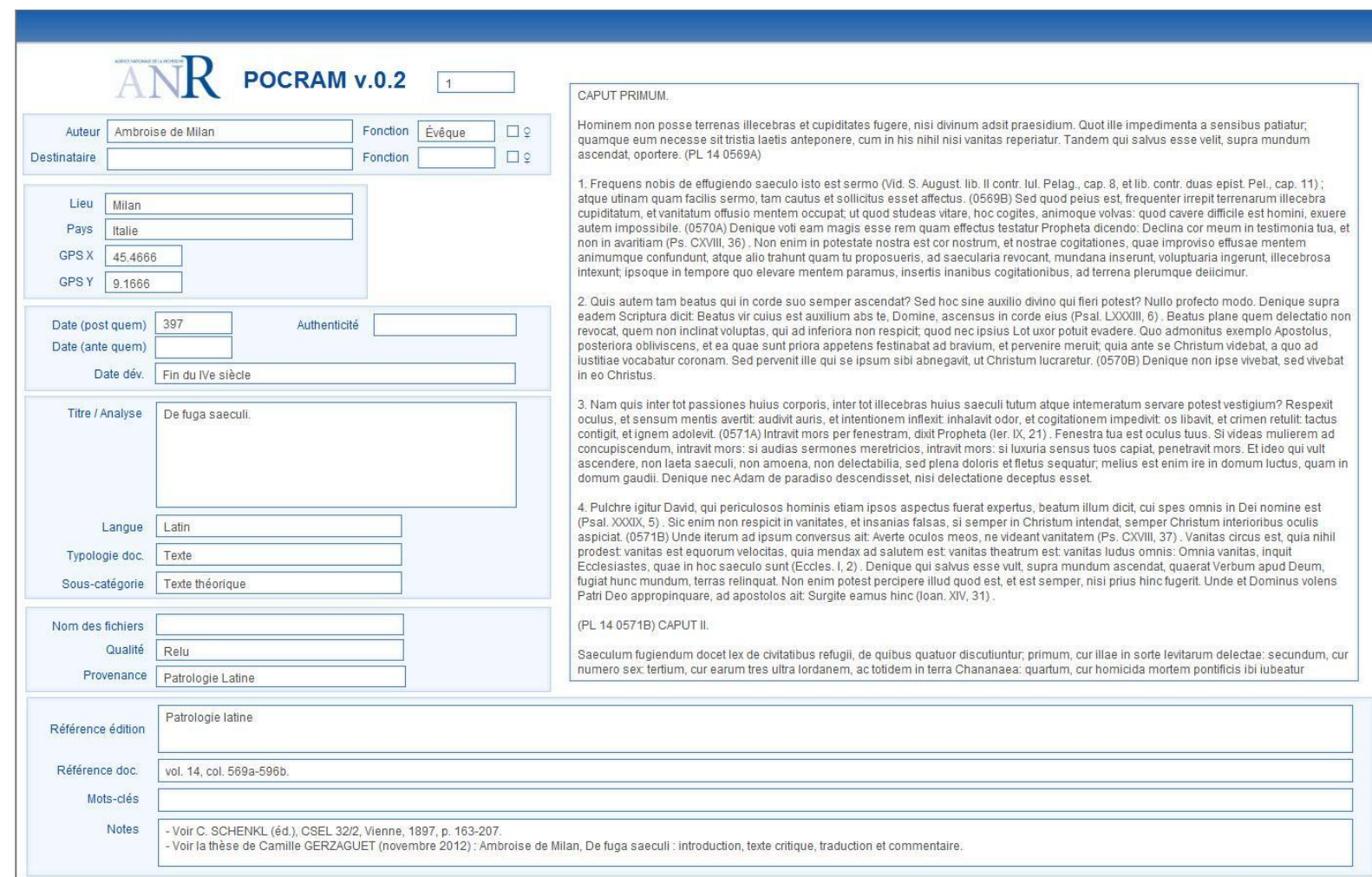

Figura 1. POCRAM, base de datos, interfaz de interrogación en FileMaker.

En una segunda fase los datos serán formateados con ayuda de un programa apropiado (Perl o Python), en función de la plataforma de acogida, TGIR-Huma-Num. Como sistema de interrogación de la base de datos, el programa desarrollado en la Universidad de Lyon, Textometrie (TXM), permite el análisis de grandes corpus textuales que integra posibilidades lexicométricas y de estadística textual, por lo cual parece ser el más acertado. Esta opción permite la importación de los textos en TXM en función de los diferentes formatos gestionados por la plataforma: TXT+CSV, texto bruto en Unicode; o bien XML/w+CSV, en formato XML (Heiden, 2010: 389-398; Heiden et al., 2010: 1021-1032).

\section{PRIMERAS EXPERIENCIAS EN TORNO A LA PATROLOGÍA LATINA}

Como se ha explicado previamente, el grado de desarrollo de la base de datos no permite manipulaciones formales muy complejas por el momento, ni a nivel lexicométrico ni a nivel semántico, ya que los textos aún no han sido integrados en su plataforma de residencia. Pero el proceso de creación del corpus nos permite apuntar algunas conclusiones, a partir del tratamiento estadístico del vocabulario latino de la Patrologia Latina, tratamiento inspirado en los trabajos realizadas por Guerreau y Perreaux (Guerreau, 2006: 149-178; Perreaux, 2014; 2015; en prensa).

El intento de explicar el término conversio y aclarar las motivaciones que conducen a este fenómeno espiritual, no es algo nuevo. Un primer precedente en esta línea, es el trabajo 
de los años '90 de Morrison, en el que se examina la temática de la conversión, en un gran número de textos desde la Antigüedad tardía al siglo $\mathrm{XX}$, centrándose particularmente en el siglo XII, momento en el cual la idea de conversión, según el autor, tiene una mayor influencia en la ética y en la psicología de Occidente (Morrison, 1992: 10-20). Morrison aborda la cuestión de la conversión espiritual, revisando la idea clásica de Nock (1933), que se define a partir de un acontecimiento que provoca una transformación, un cambio rápido y permanente, inspirado en la lectura del relato de la conversión de San Pablo en la ruta a Damasco, tomándolo como modelo para otras conversiones. También analiza el fenómeno como un acto empático, un suceso progresivo inspirado en la Imitatio Christi, diferente de la conversión formal a un nuevo credo que puede ser abandonado en cualquier momento. En su obra realiza un estudio del término conversión, analizando y comparando las distintas acepciones de la palabra conversio en los diferentes autores, delimitando sus diversas polisemias antes del siglo XII. El término es importado de las artes mecánicas, donde se aplica a la transformación de los metales, tales como el cobre o el estaño en bronce. El concepto tal y como fue empleado por paganos y cristianos en la Antigüedad, tuvo múltiples connotaciones: la emanación del cosmos para los neoplatónicos; la adopción del cristianismo por un pagano, un hereje o un judío; el rechazo del mundo para abrazar la vida monástica para un eremita; la transformación interior del hombre a imagen de Dios en el momento de la redención final. Si bien, las matizaciones de Morrison establecen provechosas bases de partida para el análisis del concepto de conversión, la utilización de herramientas que permiten el análisis conjunto de múltiples textos y perfilar las posibilidades de este concepto.

En el contexto de los evangelios, el sustantivo conversión se usa una sola vez (Hch. 15:3), y es traducción del gr. epístrofe, literalmente volverse a. La forma verbal, convertir, aparece algunas veces en forma activa (Sal. 19:7), y otras en sentido pasivo (Sal. 51:13, heb. shuf, Mt. 13:15). El significado literal de la palabra es darse vuelta, girar hacia atrás, volverse a. En sentido metafísico teológico la conversión significa que el alma se vuelve del pecado a Dios. El apartarse del pecado es el paso del arrepentimiento, y el volverse a Dios es el acto de fe mediante el cual la salvación se hace posible (Ef. 2:8, 9). Para los períodos previos al siglo XII, en el entorno semántico de la palabra conversión se localiza habitualmente un flujo de palabras que generalmente pueden estar asociadas. En este sentido, se ha realizado una lista de términos flotantes relativos al campo semántico del nombre latino conversio; la definición del campo semántico permite el análisis de categorías cruzadas, tanto en múltiples textos como en textos únicos.

El análisis léxico de la Patrología Latina permite analizar las mutaciones múltiples de significado y las diversas polivalencias del término conversio, así como examinar las estructuras de frecuencia de uso y la distribución espacial del lexema. Etimológicamente es un sustantivo derivado del verbo convertere, "volver a, transformar, mutar". Implica en muchos 
casos un cambio de naturaleza, así Jesús convierte el agua en vino, cambiando la naturaleza del objeto. La frecuencia de uso de la palabra entendida como transformación de creencia no es muy numerosa. Su campo semántico tampoco es continuo, es decir, posee mutaciones de significado en diferentes contextos, como puede verse en la figura que sigue.

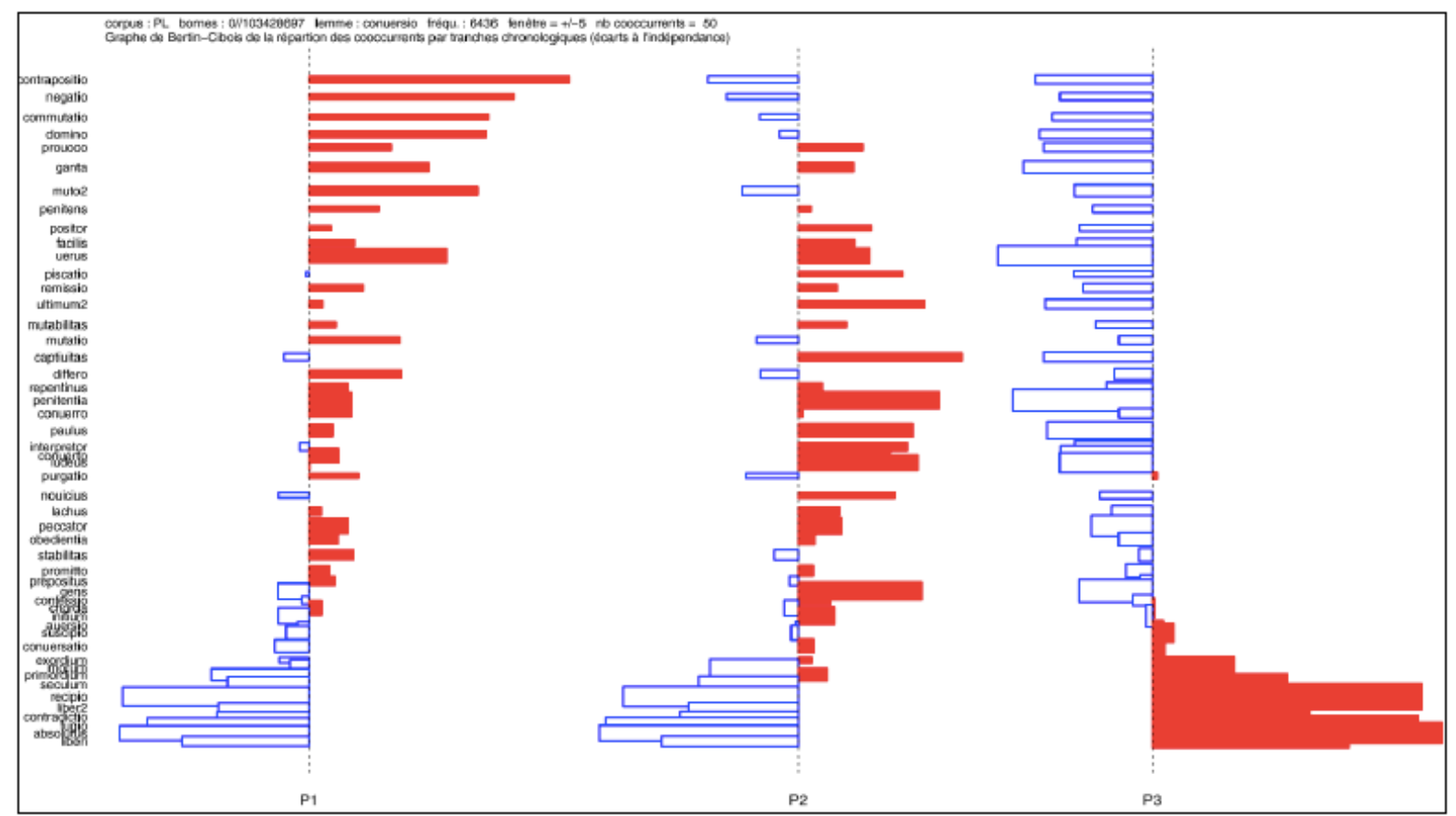

Figura 2. Patrología Latina, evolución de las concurrencias de conversio.

El término hace referencia a cambio voluntario de naturaleza asociado a múltiples vocablos: contrapositio, negatio comutatio, domino, provoco, muto, penitens, positor, facilus, creus, piscatio, inmutabilitas, differo, repentinus, penitentia, conuerro, paulus, interpretor, conuerto, iudeus, purgatio, nouicius, iacthus, peccator, obedientia, stabilitas, promitio, prepositis, gens, confessio, chorda, aversom conversatio, exordium, primordium, peccator, paenitentia, monacus, obedientia, monasterium.

La lematización de textos ha sido realizada según los parámetros desarrollados por l'ANR Omnia (Bon, 2009: 291-292; 2010: 251-252; 2011). Gracias a un programa desarrollado por Alain Guerreau (Cooc, que funciona como una interfaz entre Rcqp y CWB), es posible visualizar el corpus en franjas cronológicas que permite extraer las principales frecuencias de uso de los lemas buscados en cada sub-corpus. La experiencia permite una mejor comprensión de la evolución del contexto del lema conversio entre los siglos III-XIII. En casi todas las ocasiones hace referencia a la renuncia voluntaria a la vida laica, abjurandæ vitæ sæculari, definiendo el proceso de conversión religiosa, que implica volver el rostro a Dios, un proceso de conversión interna, tal y como definía Morrison (1992). En caso de la patrística, se 
exhorta a este tipo de práctica de volver el rostro a Dios por diferentes medios, bien sea la mediante penitencia, la confesión de la culpa, la conversatio, el diálogo, etc.

La frecuencia de asociación de conversio al cambio de credo, es decir, conversio infidelis no es muy alto, pues sólo encontramos 24 referencias. Por otra parte, la asociación entre los nombres conversio e incredulus, aporta 11 ocurrencias; conversio y judeus, 166 ocurrencias; conversio y sinagoga, 20 ocurrencias, y lo que resulta curioso, la relación entre conversio y apostasía no aparece en ninguna circunstancia. La perspectiva política del término conversio en este período no es muy frecuente. La conversión masiva incitada por reyes y señores, así como la conversión de príncipes y reyes no es muy frecuente, salvando conversiones interpretadas como modelos, tales como la de Constantino tras su visión del signo de la cruz y su bautismo al fin de su vida (Migne, 1857: I, 28, 1-29) y la conversión de Clodoveo en Reims, narrada por Gregorio de Tours (Gregorii Turonensis, 1951: II, 31-77). En ambos casos el hecho determinante de la conversión, es el bautismo: en el caso de Constantino en Nicomedia en presencia de los obispos, suceso del que existen diferentes transmisiones (Amerise, 2005); en el caso de Clodoveo en la basílica de Reims junto con sus soldados (Tessier, 1964).

En los textos latinos analizados conversio y rex aparecen asociados en 66 ocasiones, conversio y gens en 231 ocurrencias, y conversio y princeps aparecen asociados sólo en 21 fragmentos. La conversión, al margen de los idealismos hagiográficos era para los bárbaros un modo de transformarse en civilizados.

Otra de las manipulaciones formales sobre el corpus de Patrologia Latina nos permite acercarnos a las asociaciones más frecuentes de nombres y las vinculaciones entre las concurrencias, que nos proporcionan nuevas preguntas. La investigación semántica se transforma así en algo dinámico, asociado al análisis gráfico estadístico de los mismos. Ante el vacío de las respuestas asociadas a conversión y apostasía, se hizo una criba de los datos para extraer los conceptos asociados al campo semántico de la apostasía, término derivado

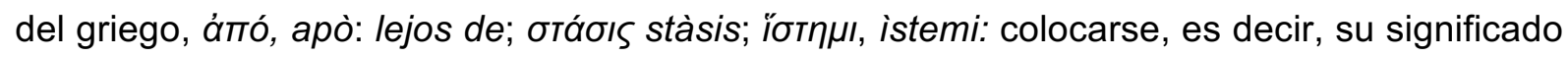
se asocia a colocarse lejos de. A la apostasía puede seguir la conversión, pero no encontramos asociaciones lingüísticas en el corpus. Sin embargo, sí se encontraron asociaciones con sacrilegum, adulterium, fornicatio, etc., siendo el diagrama de relaciones entre los términos el que se desprende del siguiente gráfico. 


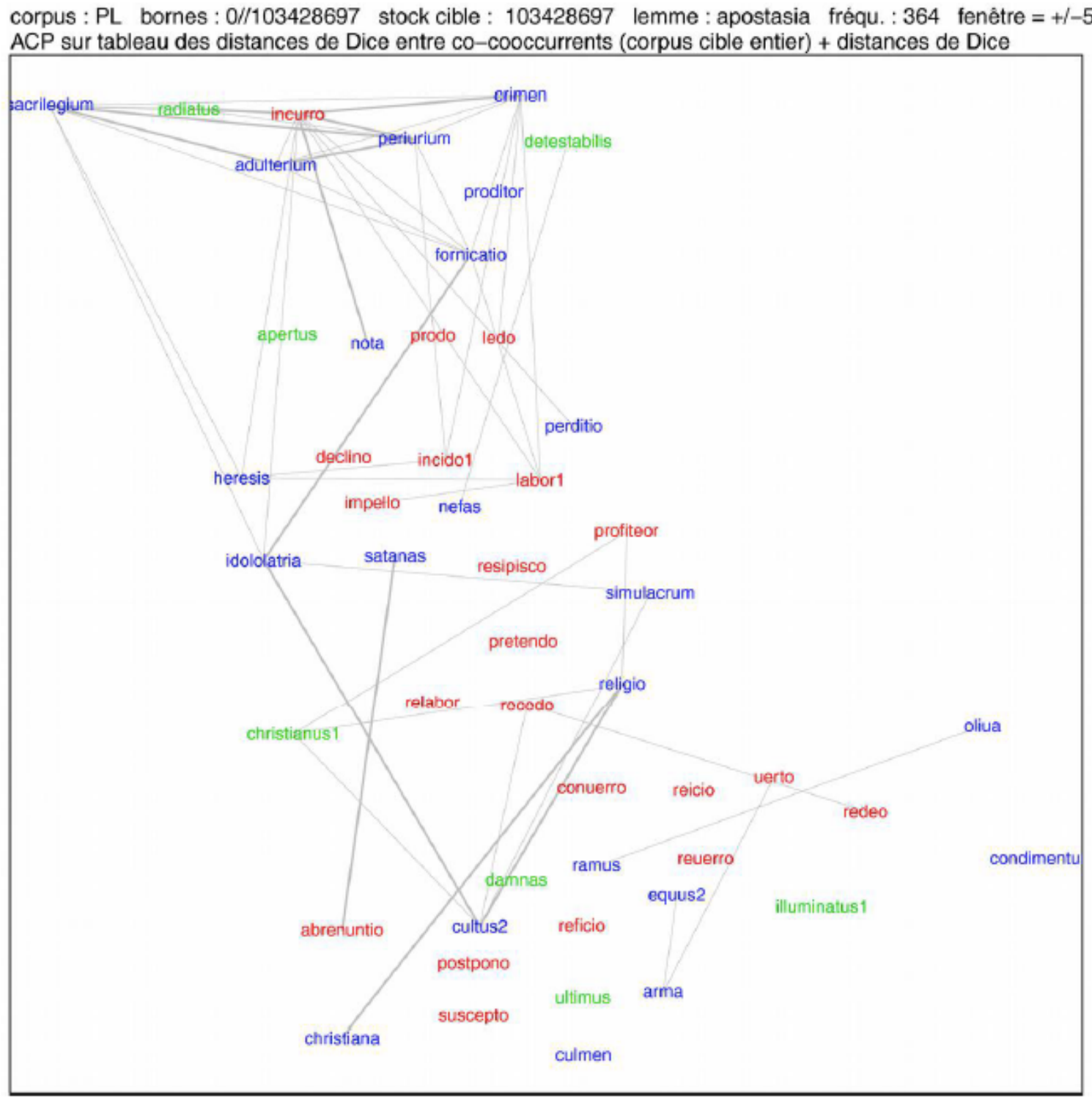

Figura 3. Patrología Latina. Red de concurrencias sobre el lema conversio (Parámetros Omnia y programa Cooc).

Este lexicograma permite un análisis de larga duración del campo semántico de un lema, y la asociación de otros lemas con los mismos, forman diferentes contextos de enunciado. Los sustantivos aparecen en azul, los calificativos en verde, los verbos en rojos.

Si aplicamos el mismo procedimiento a un corpus diferente como el legislativo y el teológico de la España medieval, los resultados serán bien diferentes, ya que el término aparece asociado casi siempre a judíos, musulmanes, idólatras, lo que nos permite conocer y precisar las rupturas, mutaciones y ampliaciones del cambio semántico.

La base de datos está en período de alojamiento, y por el momento no permite manipulaciones formales a gran escala, pero al final del proceso se espera que se convierta en una herramienta útil para este y otros tipos de análisis similares, tanto para historiadores como para filólogos. 


\section{LA DOBLE RUPTURA}

La posibilidad de la explotación textual de grandes bases de datos documentales es el reto a abordar. Los trabajos de compilación son lentos y en ocasiones tediosos, pero el diseño de herramientas que permitan la explotación conjunta de grandes corpus supone un cambio de paradigma en el quehacer histórico. No implica solamente un cambio de escala en la cantidad de documentos a utilizar en el análisis, sino un profundo cambio epistemológico, re-encuadrando el proceso de categorización de la realidad y las preguntas clave de la investigación (Berry, 2011: 1-22; Boyd y Crawford, 2012: 665-667). Las bases de datos relacionadas proponen un nuevo cambio de orden metodológico y conceptual, una ruptura del pensamiento, intrínseca a todo proceso de revolución científica. La idea se señalaba en los años 60' en la obra de Thomas Kuhn, The Structure of Scientific Revolutions, donde subraya que el progreso no es lineal, sino que se produce a través de una serie de rupturas, que dan lugar a nuevos paradigmas de interpretación (Kuhn, 1962: 44-66). Rupturas necesarias y que se producen por la introducción de nuevos métodos de análisis, que provocan el cambio del modelo interpretativo y de las preguntas al contexto de análisis (McCarty, 2012: 113-123).

Los cambios introducidos por la explotación digital de los datos modifican los paradigmas formalmente aceptados por los historiadores, surgen nuevos modelos de interpretación, producto del cambio de escala en el análisis. En los últimos tiempos, el gran número de proyectos dedicados a las bases de datos en ciencias humanas se han multiplicado, las posibilidades de análisis y las herramientas digitales han permitido la reconstrucción de las lógicas globales del occidente antiguo, medieval y moderno. Pero no siempre la acumulación de datos es la solución. Los modelos creados a partir de bases de datos estáticas, en las que la acumulación de material es prioritaria, son importantes para la conservación y difusión documental, pero no permiten la explotación posterior. ¿La acumulación de datos provoca la renovación de una ciencia en crisis? ¿Es posible la duda? (Kuhn, 1962: 43-66).

La digitalización de textos y documentos de la época antigua, medieval y moderna invitan a una doble ruptura de orden metodológico y conceptual. En otros términos, se trata de inventar un cuestionario científico y un dispositivo técnico que permita el almacenamiento y la reestructuración posterior de cara a la explotación colectiva Data/Text Mining (Perreaux, 2014: 193; en prensa), lo que facilita el análisis posterior y la creación de nuevas preguntas.

La segunda ruptura está intrínsecamente relacionada con la naturaleza de las fuentes (Guerreau, 2001a: 163-190). En el caso de análisis, todos los textos analizados corresponden al período pre-moderno, y son utilizados en su lengua originaria, observan cómo una misma palabra pudo mutar su significado o complementarlo en el curso de los siglos. La re- 
contextualización semántica de los conceptos evita contaminaciones e interpretaciones contemporáneas que desvirtúan los procesos.

Teniendo en cuenta todo lo señalado, la concepción de esta base de datos y el proceso de acumulación de los mismos nos ha permitido desarrollar diferentes hipótesis en cuanto al sentido de la conversión en el período medieval. Como se ha remarcado, la conversión religiosa debe ser diferenciada de la conversio, conceptos que no se superponen más que parcialmente. El primer análisis de la acumulación documental, nos ha hecho reparar en un fenómeno crono-geográfico remarcable: los documentos que evocan la conversión religiosa en el sentido de cambio radical de un sistema de creencias a otro, aparecen esencialmente en las periferias del sistema medieval, bien sea geográfica o cronológicamente. Esta tendencia es coherente con lo que sabemos de la dinámica europea, en tanto y en cuanto, la conversión se asocie a interacciones entre sociedades (cristianas, y no cristianas) y sólo pueda de facto aparecer en los márgenes del sistema eclesial. Esto explica por qué la mayor parte de nuestra documentación que evoca la conversio en sentido de cambio profundo de creencia, aparece sobre todo en la Antigüedad Tardía, la Alta Edad Media y el fin de la Edad Moderna, así como, en ciertos espacios límites del sistema, donde las interacciones entre las diferentes sociedades son fuertes: espacios fronterizos de la Península Ibérica, espacios germánicos, y las Islas Británicas en la Alta Edad Media.

Este análisis de la producción documental relativa a la conversio despierta el profundo interés de estudiar la existencia de los textos en función de sus espacios y contextos de elaboración. La conversión religiosa aparece por tanto como un fenómeno marginal en sentido cuantitativo y sistemático, en el sentido de que es escasa y no define más que parcialmente, el sentido del lema conversio, pero paradójicamente es determinante para la comprensión semántica de las interacciones transculturales en la Edad Media.

\section{REFERENCIAS BIBLIOGRÁFICAS}

ALBERIGO, J.M. (1973). Conciliorum Oecumenicorum Decreta. $3^{\text {a }}$ ed. Bolonia: Istituto per le Scienze Religiose.

ÁLVAREZ-CARBAJAL, F.J. (2014). "Review of 'The Digital Edition of the Becerro Galicano de San Millán de la Cogolla'”. RIDE 2. Recuperado de http://ride.i-d-e.de/issues/issue2/becerro-galicano/ el 19/02/2017.

AMERISE, M. (2005). I/ battesimo di Costantino il Grande. Storia di una scomoda ereditá. Stuttgart: Steiner. 
AMRÁN, R. (2009). Judíos y conversos en el Reino de Castilla: propaganda y mensajes políticos, sociales y religiosos (siglos XIV y XVI). Valladolid: Junta de Castilla y León.

BAER, F. (1929-1936). Die Juden im christlichen Spanien. 2 vols. Berlin: Akademie Verlag.

BENAVENTE, T. De (1913). Historia de los Indios de Nueva España. Madrid: Herederos de Juan Gili.

BERRY, D. (2011). "The Computational Turn: Thinking About the Digital Humanities”. Culture Machine, 12, 1-22.

BON, B. (2009). "OMNIA-Outils et Méthodes Numériques pour l'Interrogation et l'Analyse des Textes Médiolatins". Bulletin du Centre d'Études Médiévales d'Auxerre (BUCEMA), 13, 291-292. Recuperado de http://cem.revues.org/11086 el 17/02/2017. (2010). “OMNIA-Outils et Méthodes Numériques pour l'Interrogation et l'Analyse des Textes Médiolatins (2)". Bulletin du Centre d'Études Médiévales d'Auxerre (BUCEMA), 14, 251-252. Recuperado de http://cem.revues.org/11566 el 17/02/2017. (2011). "OMNIA-Outils et Méthodes Numériques pour l'Interrogation et l'Analyse des Textes Médiolatins (3)". Bulletin du Centre d'Études Médiévales d'Auxerre (BUCEMA), 15. Recuperado de http://cem.revues.org/12015 el 17/02/2017.

BORSARI, E. y CALVO TELLO, J. (2013). "Catálogo hipertextual de traducciones anónimas al castellano (CHTAC). Un nuevo proyecto de Humanidades Digitales”. Mirabilia, 15, 203-226.

BOUCHERON, P. y DELALANDE, N. (2013). Pour une histoire-monde. París: Presses Universitaires de France.

BOURLET, C. (1979). "Voyage au centre de... Poitiers". Le Médiéviste et l'ordinateur, 1, 1112.

BOYD, D. y CRAWFORD, K. (2012). "Critical Questions for Big Data". Information, Communication and Society, 15.5, 662-679. Recuperado de http://dx.doi.org/10.1080/1369118X.2012.678878 el 17/02/2017.

BRAUDEL, F. (1958). "Histoire et Sciences Sociales. La longue durée". Annales ESC, 13.4, 725-753.

BUSA, R. (ed.) (1992). Thomae Aquinatis Opera Omnia Cum Hypertextibus in CD-ROM. Milano: Editoria Elettronica Editel.

CARRASCO MANCHADO, A.I. (2012). De la convivencia a la exclusión. Imágenes legislativas de mudéjares y moriscos. Siglos XIII-XVII. Madrid: Silex.

CASTAGNOLI, A. (1987). L'ipotesi del "campo semantico" di Jost Trier ed I suoi riflessi nella linguistica contemporánea. Pisa: Universita degli Studi di Pisa.

CLAVERT, F. y NOIRET, S. (2013). L'histoire contemporaine à l'ère numérique. Bruxelles: Peter Lang. 
COHEN, J. (1991). Essential Papers on Judaism and Christianity in Conflict from Late Antiquity to Reformation. New York: New York University Press.

CROUZET, D. (2008). "Dieu en ses royaumes: une histoire des guerres de religión”. Archives de sciences sociales des religions, 148, 75-342.

DAVIDSON, C.N. (2008). "Humanities 2.0: Promise, Perils, Predictions". Publications of the Modern Language Association of America (PMLA), 123. 3, 707-717.

DE AQUINO, T. (1888). Summa Theologica. S. Thomae de Aquino Opera Omnia, IV. Romae: Editio Leonina.

DE LA TORRE, A. (ed.) (1962). Documentos sobre relaciones internacionales de los Reyes Católicos: 1492-1494, vol. IV, Barcelona: Consejo Superior de Investigaciones Científicas, Patronato Marcelino Menéndez Pelayo.

DEEGAN, M. y SUTHERLAND, K. (2009). Text Editing, Print and the Digital World. FarnhamBurlington: Asghate.

DÍAZ DEL CASTILLO, B. (1930). Historia verdadera de la conquista de la Nueva España. México DF: Joaquin Rodriguez Cabañas.

DULONG DE ROSNAY, M. (2016). Les Golems du numérique. Droit d'auteur et Lex Electronica. Paris: Presses des Mines.

DUMEZIL, B. (2005). Les Racines chrétiennes de l'Europe. Conversion et liberté dans les royaumes barbares, $V^{e}-V_{I I I}^{e}$ siècles. Paris: Fayard.

ECHEVARRIA ARSUAGA, A. (2006). “La 'mayoría' mudéjar en León y Castilla: legislación real y distribución de la población, (siglos XI-XIII)". En la España Medieval, 29, 7-30.

FERNÁNDEZ y GONZÁLEZ, F. (1866). Estado social y político de los mudéjares de Castilla. Madrid: Real Academia de la Historia.

FONTANON, A. (1611). Les Édicts et ordonnances des rois de France depuis Louis VI, dit le Gros, jusques à présent... par Antoine Fontanon... et de nouveau reveuz... et augmentez... par Gabriel Michel... [sieur de La Rochemaillet]. París: s.n.

FOSSIER, L. (1991). "Vingt ans d'informatique en histoire médiévale". En Actes des congrès de la Société des historiens médiévistes de l'enseignement supérieur public. L'histoire médiévale en France. Bilan et perspectives. $20^{e}$ Congrès, Paris, 1989, M. Balard (ed.), 501-525. Paris: Seuil.

FOSSIER, L., VAUCHEZ, A. y VIOLANTE, C. (dir.) (1977). Informatique et histoire médiévale: communications et débats de la Table ronde C.N.R.S., Organisée par l'École française de Rome et l'Institut d'histoire médiévale de l'Université de Pisa, Rome. 20-22 mai 1975. Rome: École française de Rome.

FOUCAULT, M. (1966). Les mots et les choses. Paris: Gallimard.

FRIEDBERG, E. (ed.) (1879). Decretum Magistri Gratiani, Corpus Iuris Canonici, vol. 1. Leipzig: Bernhard Tauchnitz. 
FRIEDBERG, E. y RICHTER, E.L. (eds.) (1881). “Liber Extra Decretalii Gregorii IX Compilatio, Corpus luris Canonici, Pars Secunda: Decretalium Collectiones”. Decretales Gregorii, IX. Leipzig: Bernhard Tauchnitz.

FRUGONI, A. (ed.) (1957). Gioacchino da Fiore. Adversus Judeos. Fonti per la storia d'Italia, 95. Roma: Instituto Storico italiano per el Medioevo.

GARCíA ICAZBALCETA, J. (1858). Colección de documentos para la historia de México. México: Librería J. de Andrade.

GARDIN, J.C. (1994). "Informatique et progrès dans les sciences de l'homme". Revue informatique et statistique dans les sciences humaines, 30 année, 1.4, 11-35.

GENET, J.P. (1986). “Histoire, Informatique, Mesure”. Histoire \& Mesure, 1, 7-18. (2011). "Introduction". En Les historiens et l'informatique: un métier à reinventer, J.P. Genet, A. Zorzi et al. (eds), 1-9. Roma: Ecole Française de Rome.

GONZÁLEZ-BLANCO, E. (2013). "Actualidad de las Humanidades Digitales y un ejemplo de ensamblaje poético en la red". Cuadernos Hispanoamericanos, 761, 53-68.

(2016). "Un nuevo camino hacia las Humanidades Digitales: el Laboratorio de Innovación en Humanidades Digitales de la UNED (LINHD)". Signa: Revista de la Asociación Española de Semiótica, 25, 79-93.

GOODY, J. (2006). The Theft of History. Cambridge: Cambridge University Press.

GORCY, G. (1983). "L'informatique et la mise en oeuvre du Trésor de la Langue Française (TLF), dictionnaire de la langue du $19^{\mathrm{e}}$ et du $20^{\mathrm{e}}$ siècle (1789-1960)". En Linguistica Computazionale III: The Possibilities and Limits of the Computer in Producing and Publishing Dictionaries: Proceedings of the European Science Foundation Workshop. Pisa, A. Cappelli y A. Zampolli (eds.), 119-144. Pisa: Giardini.

GREGORII TURONENSIS (ed.) (1951). "Decem Libri Historiarum". Scriptres Rerum Merovingiarum. Hannover: B. Krusch, W. Levinson, MGH.

GUERREAU, A. (2001a). L'avenir d'un passé incertain. Quelle histoire du Moyen Âge au XXI' siècle?. Paris: Seuil.

(2001b). "Vinea". En Les historiens et le latin médiéval, M. Goullet y M. Parisse, (eds.), 67-73. Paris: Publications de la Sorbonne.

(2006). "Textus chez les auteurs latins du XII siècle". En "Textus" im Mittelalter, L. Kuchenbuch y U. Kleine (eds.), 149-178. Göttingen: Vandenhoeck \& Ruprecht. (2012). "Textes anciens en série. Outils informatiques d'organisation et de manipulation de bases de données textuelles". Bulletin du Centre d'Études Médiévales d'Auxerre (BUCEMA). Recuperado de http://cem.revues.org/12177 el 19/02/2017.

(2015). L'avenir de la Philologie. Textes anciens et domaine public. Paris: HAL-SHS. Recuperado de https://halshs.archives-ouvertes.fr/halshs-01112213/document el 19/02/2017. 
HALL, G. (2012). “There Are No Digital Humanities". En Debates in the Digital Humanities, M.K. Gold (ed.), 133-136. Minneapolis: University of Minnesota Press.

HEIDEN, S. (2010). "The TXM Platform: Building Open-Source Textual Analysis Software Compatible with the TEI Encoding Scheme". En 24 ${ }^{\text {th }}$ Pacific Asia Conference on Language, Information and Computation, R.K Ryo Otoguro et al. (eds.), 389-398. Sendai: Institute for Digital Enhancement of Cognitive Development, Waseda University.

HEIDEN, S., MAGUÉ, J-P. y PINCEMIN, B. (2010). "TXM: Une plateforme logicielle opensource pour la textométrie-conception et développement". En Proc. of 10th International Conference on the Statistical Analysis of Textual Data, JADT 2010, S. Bolasco (ed.), vol. 2, 1021-1032. Roma: Edizioni Universitarie di Lettere Economia Diritto.

HOCKEY, S. (2004). "The History of Humanities Computing". En A Companion to Digital Humanities, S. Schreibman, R. Siemens y J. Unsworth (eds.). Oxford: Blackwell. Recuperado de http://www.digitalhumanities.org/companion/ el 19/02/2017.

JUSSEN, B., MEHLER, A. y ERNST, A. (2007). "A Corpus Management System for Historical Semantics". Sprache und Datenverarbeitung. International Journal for Language Data Processing, 31, 81-89.

JUSSEN, B., MEHLER, A., SCHWANDT, S. y GLEIM, R. (2011). "Der eHumanities Desktop als Werkzeug in der historischen Semantik: Funktionsspektrum und Einsatzszenarien". Zeitschrift für Computerlinguistik und Sprachtechnologie. Journal for Language Technology and Computational Linguistics, 26, 97-117.

KEMPER, J. y VOGELER G. (2011). Digitale Urkundenpräsentationen. Beiträge zum Workshop in München 16. Juni 2010. Schriften des Instituts für Dokumentologie und Editorik, 6. Norderstedt: $\mathrm{GmbH}$.

KIRSCHENBAUM, M.G. (2010). "What is Digital Humanities and What is Doing in English Departments?". ADE Bulletin, 150, 1-7.

KUHN, T. (1962). The Structure of Scientific Revolutions, Chicago: University of Chicago Press.

LAS CASAS, B. de (1821). Breve relación de la destrucción de las Indias Occidentales presentada a Felipe II, siendo Príncipe de Asturias. Filadelfia: J. Hurtel.

LE CLECH, S. (2012). "Humanités numériques, ou la nouvelle diáspora". Bulletin du Centre d'Études Médiévales d'Auxerre (BUCEMA). Recuperado de http://cem.revues.org/12283 el 19/02/2017.

MAGNANI, E. (2013). "L'échange dans la documentation diplomatique bourguignonne: autour d'un champ sémantique". En L'acte d'échange, du VIII au XII' siècle, P. Depreux e I. Fees (dirs.), 13, 403-426. Köln-Weimar-Wien: Böhlau Verlag. 
MAGNANI, E., GASSE-GRANDJEAN, M.J. (2005). "Chartae Burgundiae Medii Aevi (CBMA). Les debuts du projet". Bulletin du Centre d'tudes Médiévales d'Auxerre (BUCEMA), 9, 179-181. Recuperado de http://cem.revues.org/751 el 20/02/2017. (2007). "Chartae Burgundiae Medii Aevi. 1. Les fonds diplomatiques bourguignons". Bulletin du Centre d'Études Médiévales d'Auxerre (BUCEMA), 11, 163-169. Recuperado de http://cem.revues.org/1064 el 20/02/2017. (2008). "Chartae Burgundiae Medii Aevi. II. Cartulaires, éditions, base de données". Bulletin du Centre d'Études Médiévales d'Auxerre (BUCEMA), 12, 237-244. Recuperado de http://cem.revues.org/6962 el 20/02/2017. (2009). "Chartae Burgundiae Medii Aevi. III. Systèmes d'interrogation et recherches sur les fonds diplomatiques bourguignons". Bulletin du Centre d'Études Médiévales d'Auxerre (BUCEMA), 13, 245-251. Recuperado de http://cem.revues.org/11077 el 20/02/2017.

(2010). "Chartae Burgundiae Medii Aevi. IV. Études, Éditions, Historiographie”. Bulletin du Centre d'Études Médiévales d'Auxerre (BUCEMA), 14, 197-209. Recuperado de http://cem.revues.org/11556 el 20/02/2017.

MAGNANI, E., GASSE-GRANDJEAN, M.J., REY, C. y PERREAUX N. (2013). "Les Chartae Burgundiae Medii Aevi (CBMA). Du parchemin à l'écran". La lettre de l'InSHS, La Tribune d'Adonis, 22, 27-30.

MANNING, C.D., RAGHAVAN, P. y SCHÜTZE, H. (2008). Introduction to Information Retrieval. Cambridge: Cambridge University Press.

MARCHE S. (2012). "Literature is not Data: Against Digital Humanities”. Los Angeles Review of Books. Recuperado de http://lareviewofbooks.org/essay/literature-is-not-dataagainst-digital-humanities el 19/02/2017.

McCARTY, W. (2003). "Humanities Computing". En Encyclopedia of Library and Information Science, W. McCarty y M. Drake (eds.), 1224-1235. New York: Marcel Dekker. (2012). “A Telescope for the Mind?". En Debates in the Digital Humanities, M. K. Gold (ed.), 113-123. Minneapolis: University of Minnesota Press.

MIGNE, J.P. (ed.) (1857). Patrologia Graeca, vol. 20, col. 942. Recuperado de http://patristica.net/graeca/\#t020 el 17/02/2017.

MORRISON, K.F. (1992). Understanding Conversion. Charlottesville-London: University of Virginia Press.

NIRENBERG, D. (2014). Neighboring Faiths. Chicago: University Chicago Press.

NOCK, A.D. (1933). Conversion. The Old and the New in Religion from Alexander the Great to Augustine the Hiponne. Oxford: Oxford University Press.

PERREAUX, N. (2011). "L'eau, l'écrit et la société (IX'-XII siècle). Étude statistique sur les champs sémantiques dans les bases de données [CBMA et autres]". Bulletin du Centre 
d'Études Médiévales d'Auxerre (BUCEMA), 15, 439-449. Recuperado de http://cem.revues.org/index12062.html el 20/02/2017.

(2014). “De l'accumulation à l'exploitation? Expériences et propositions pour l'indexation et l'utilisation des bases de données diplomatiques". En Digital Diplomatics, A. Ambrosio, S. Barret y G. Vogeler (eds.), 187-211. Weimar: Böhlau Verlag Köln.

(2015). "L'écriture du monde (I). Les chartes et les édifices comme vecteurs de la dynamique sociale dans l'Europe médiévale (VII ${ }^{\mathrm{e}}$-milieu du $\mathrm{XIV}^{\mathrm{e}}$ siècle)". Bulletin $d u$ Centre d'Études Médiévales d'Auxerre (BUCEMA), 19.2. Recuperado de https://cem.revues.org/14264 el 20/02/2017.

(en prensa). L'écriture du monde. Dynamique, perception, catégorisation du mundus au Moyen Âge (VII - -XIII siècles). Recherches à partir des bases de données numérisées. Leyden: Brepols.

PERREAUX, N. y REY, C. (2013). "CBMA. Chartae Burgundiae Medii Aevi. VII. Le 'vocabulaire courant' en diplomatique: techniques et approches comparées”. Bulletin du Centre d'Études Médiévales d'Auxerre (BUCEMA). Recuperado de http://cem.revues.org/13172 el 20/02/2017.

PETERSON, D. (2009). "Reescribiendo el pasado. El Becerro Galicano como reconstrucción de la historia institucional del monasterio de San Millán de la Cogolla”, Hispania. Revista Española de Historia, 23, 653-682.

PIERAZZO, E. et al. (eds.) (2010). Digital Humanities 2010. Conference abstracts. King's College London, 7-10 July 2010. London. King's College.

POUTRAIN, I. (2012). Convertir les musulmans. Espagne, 1491-1609. Paris: Presses Universitaires de France.

PRIANI SAISÓ, E., SPENCE, P., GALINA RUSSELL, I. et al. (2014). "Las Humanidades Digitales en español y portugués. Un estudio de caso: DíaHD/DiaHD”. Anuario Americanista Europeo, 12, 5-19.

REHBEIN M., SAHLE, P. y SCHAßAN, T. (dirs.) (2009). Codicology and Palaeography in the Digital Age I. Norderstedt: Schriften des Instituts für Dokumentologie und Editorik. Recuperado de http://kups.ub.uni-koeln.de/2939/ el 20/02/2017.

ROBIN, R. (1973). Histoire et Linguistique. Paris: Armand Colin.

ROSÉ, I. (2008). "À propos des Chartæ Burgundiæ Medii ÆEvii (CBMA). Éléments de réflexion à partir d'une enquête sur la dîme en Bourgogne au Moyen Âge". Bulletin du Centre d'Études Médiévales d'Auxerre (BUCEMA), 12. Recuperado de http://cem.revues.org/8412 el 20/02/2017.

ROMANELLO, M., BERTI, M., BOSCHETTI, F., BABEU, A. y CRANE, G. (2009). "Rethinking Critical Editions of Fragmentary Text by Ontologies". En Proceedings on $13^{\text {th }}$ International Conference on Electronic Public: Rethinking Electronic Publishing, 
Innovation in Communication Paradigms and Technologies, S. Mornati y T. Hedlund (eds.), 155-174. Milano.

SCHMIDT, L. (ed.) (1973). Wortfeldforschung: zur Geschichte und Theorie des sprachlichen Feldes. Darmstadt: Wissenschaftliche Buchgesellschaft.

SCHOLZ, R. (ed.) (1931). MGH Fontes iuris germanici antiquis. Marsilio de Padua, Defensor pacis. Hannover: Hahnsche Buchhandlung.

SCHREIBMAN, S., SIEMENS, R. y UNSWORTH, J. (2004). A Companion to Digital Humanities. Oxford: Blackwell. Recuperado de http://www.digitalhumanities.org/companion/ el 20/02/2017.

STEVENS, R. y MOORMAN, D. (2006). Mind Technologies. Humanities Computing and the Canadian Academy Community. Calgary: University of Calgary Press.

SUÁREZ FERNÁNDEZ, L. (1964). Documentos acerca de la expulsión de los judíos. Valladolid: CSIC.

SVENSSON, P. (2009). "Humanities Computing as Digital Humanities". Digital Humanities Quarterly, 3.3 Recuperado de http://www.digitalhumanities.org/dhq/vol/3/3/000065/000065.html el 20/02/2017. (2010). "The Landscape of Digital Humanities". Digital Humanities Quarterly, 4. 1. Recuperado de http://www.digitalhumanities.org/dhq/vol/4/1/000080/000080.html el 20/02/2017.

(2011). "From Optical Fiber to Conceptual Cyberinfrastructure". Digital Humanities Quarterly, $\quad 5 . \quad 1 . \quad$ Recuperado de http://www.digitalhumanities.org/dhq/vol/5/1/000090/000090.html el 20/02/2017. (2012). "Envisioning the Digital Humanities". Digital Humanities Quarterly, 6. 1. Recuperado de http://www.digitalhumanities.org/dhq/vol/6/1/000112/000112.html el 20/02/2017.

TESSIER, G. (1964). Le Baptême de Clovis. Paris: Gallimard.

THIEULIN-PARDO, H. (2010). "Reflexiones en torno a una edición digital del Liber regum (o Libro de las generaciones y linajes de los reyes)". e-Spania, 9. Recuperado de http://espania.revues.org/19863 el 20/02/2017.

TOCK, B.M. (2001). "La diplomatique française du Haut Moyen Âge vue à travers les originaux". En La diplomatique française du haut Moyen Age, inventaire des chartes originales antérieures à 1121 conservées en France, B.M. Tock, M. Courtois, M.J. Gasse-Grandjean (dirs.), 1-37. Turnhout: Brepols.

TRIER, J. (1931). Der Deutsche Wortschatz im Sinnbezirk des Verstandes: Die Geschichte eines sprachlichen Feldes, Band 1: Von den Anfängen bis zum Beginn des 13 Jahrhunderts. Heidelberg: Winter. 
VOGELER, G. (dir.) (2009). Digitale Diplomatik: neue Technologien in der historischen Arbeit mit Urkunden. En Archiv für Diplomatik, Schriftgeschichte, Siegel-und Wappenkunde. Beihefte, 12. Weimar-Wien- Köln: Böhlau Verlag.

WALLERSTEIN, I. (2004). World-Systems Analysis: An Introduction. Durham: Duke University Press.

WELLER, T. (ed.) (2012). History in the Digital Age. Abingdon-New York: Routledge.

WITTEN, I.H., FRANK, E. y HALL, M.A. (2011). Data Mining: Practical Machine Learning Tools and Techniques. Burlington: Elsevier. 